\title{
Prevalência da infecção endocervical de Chlamydia trachomatis em universitárias do estado do Pará, Região Amazônica, Brasil
}

\section{Prevalence of endocervical Chlamydia trachomatis infection in university students from Pará State, Amazon Region, Brazil}

Leonardo Miranda dos Santos', Wlyana Lopes Ulian², Josinaide Quaresma Trindade², Francisca Dayse Martins de Sousa ${ }^{2}$, Jessica Fernanda Galdino Oliveira ${ }^{2}$, Cássia Cristine Costa Pereira ${ }^{1}$, Danielle Murici Brasiliense ${ }^{3}$, Benedito Antônio dos Prazeres², Mihoko Yamamoto Tsutsumi², Edna Aoba Yassui Ishikawa', Maísa Silva de Sousa'

\footnotetext{
' Universidade Federal do Pará, Núcleo de Medicina Tropical, Laboratório de Biologia Molecular e Celular, Belém, Pará, Brasil

2 Universidade Federal do Pará, Instituto de Ciências Biológicas, Laboratório de Citopatologia, Belém, Pará, Brasil

${ }^{3}$ Instituto Evandro Chagas/SVS/MS, Seção de Bacteriologia e Micologia, Laboratório de Biologia Molecular e Celular, Ananindeua, Pará, Brasil
}

\begin{abstract}
RESUMO
OBJETIVOS: Descrever a prevalência e os fatores associados à infecção endocervical por Chlamydia trachomatis em estudantes de uma universidade da capital e de três de seus campi do interior do estado do Pará, Amazônia, Brasil. MATERIAIS E MÉTODOS: Estudo transversal, com mulheres de idade igual ou superior a 18 anos, que realizaram o preventivo do câncer do colo uterino, de setembro de 2010 a outubro de 2014. O DNA da secreção cérvico-vaginal foi extraído pelo método fenol-clorofórmio e submetido à amplificação dos genes da $\beta$-globina humana e ompA de $C$. trachomatis por reação em cadeia da polimerase. Foram utilizados os testes de Mann-Whitney, estimação da proporção e odds ratio para análises estatísticas. $O p \leq 0,05$ foi considerado estatisticamente significativo para um intervalo de confiança (IC) de 95\%. RESULTADOS: A prevalência de C. trachomatis foi de $11,9 \%$ [54/454 (IC 95\% 8,9-14,9)]. A infecção foi identificada em 10,4\% [36/345 (IC 95\% 7,2-13,7)] das estudantes da Capital e em 16,5\% [18/109 (IC 95\% 10,3-24,6)] das estudantes dos campi do interior $(p=0,12)$, sendo de 7,1\% (2/28) no Interior 1, 22,2\% (6/27) no Interior 2 e 18,5\% (10/54) no Interior 3. Não foi observada associação entre as variáveis investigadas e a infecção endocervical por C. trachomatis. CONCLUSÃO: A prevalência da infecção por C. trachomatis entre as universitárias se assemelhou à média encontrada no Brasil e não se mostrou associada às condições sociodemográficas e comportamentais das universitárias investigadas.
\end{abstract}

Palavras-chave: Doenças Bacterianas Sexualmente Transmissíveis; Doenças Negligenciadas; Estudos Transversais.

\begin{abstract}
OBJECTIVES: To describe the prevalence and factors associated with endocervical infection by Chlamydia trachomatis in students from a university in the capital and three campuses in inland towns of Pará State, Amazon, Brazil. MATERIALS AND METHODS: A cross-sectional study with women aged 18 years or older who underwent cervical cancer prevention from September 2010 to October 2014. DNA from cervicovaginal secretion was extracted using the phenol-chloroform method and subjected to the amplification of the human $\beta$-globin and ompA genes of C. trachomatis by polymerase chain reaction. Mann-Whitney tests, proportion estimation, and odds ratio were used for statistical analysis. The $p \leq 0.05$ was considered statistically significant for a confidence interval (Cl) of 95\%. RESULTS: The prevalence of C. trachomatis was 11.9\% [54/454 (95\% Cl 8.9-14.9)]. Infection was identified in $10.4 \%[36 / 345(95 \% \mathrm{Cl} 7.2-13.7)]$ of the students in the Capital and in $16.5 \%$ [18/109 $(95 \% \mathrm{Cl} 10.3-24.6)$ of students from the campuses in the inland towns $(p=0.12)$, with $7.1 \%(2 / 28)$ in the Town 1, 22.2\% (6/27) in the Town 2, and 18.5\% (10/54) in the Town 3. No association between the investigated variables and the endocervical infection by $C$. trachomatis was observed. CONCLUSION: The prevalence of $C$. trachomatis infection among those university students was similar to the average found in Brazil and was not associated with the sociodemographic and behavioral conditions of the university students investigated.
\end{abstract}

Keywords: Bacterial Sexually Transmitted Diseases; Neglected Diseases; Transversal Studies.

\author{
Correspondência / Correspondence \\ Leonardo Miranda dos Santos \\ Núcleo de Medicina Tropical, Universidade Federal do Pará \\ Av. Generalíssimo Deodoro, 92. Bairro: Umarizal - CEP: 66055-240 - Belém, Pará, Brasil - Tel./Fax: +55 (91) $3201-0960$ \\ E-mail: leonn_bio20@yahoo.com.br
}




\section{INTRODUÇÃO}

A Chlamydia trachomatis é responsável pela infecção sexualmente transmissível (IST) bacteriana mais prevalente no mundo, além de ser a causa mais comum de infertilidade evitável e frequentemente identificada nos grandes centros urbanos ${ }^{1,2,3,4}$. Possui 19 genótipos, que estão relacionados a três formas clinicamente distintas dessa infecção: o tracoma, causado pelos genótipos $A$, $\mathrm{B}, \mathrm{Ba}$ e $\mathrm{C}$, considerado a principal causa de cegueira evitável no mundo ; o linfogranuloma venéreo, causado pelos genótipos L1, L2, L2a e L3, uma IST que se estabelece predominantemente com caráter invasivo; e manifestações clínicas bem específicas, como a linfadenopatia inguinal ${ }^{6}$. Os genótipos $D$, Da, E, F, G, Ga, H, I, la, J e K estão associados a infecções urogenitais não invasivas, que são assintomáticas em até $80,0 \%$ das mulheres e podem determinar sequelas severas no aparelho reprodutivo feminino, como doença inflamatória pélvica, gravidez ectópica e aborto espontâneo ${ }^{7,8,9}$.

No Brasil, a prevalência de infecções por C. trachomatis varia entre $4,3 \%$ e $31,0 \%$, conforme estudos de base populacional/comunitária de grandes centros urbanos e estudos de base clínica, realizados com participantes frequentadoras de ambulatórios e clínicas ginecológicas ${ }^{10,11,12,13,14,15,16,17,18,19}$. Nas comunidades amazônicas, há escassez de conhecimento sobre a epidemiologia da infecção endocervical por $C$. trachomatis, o que impossibilita a criação de diretrizes que estabeleçam o rastreio e controle dessa infecção.

Os testes de amplificação de ácidos nucleicos (NAAT) são recomendados para o screening dessa infecção, apresentam alto padrão de sensibilidade e especificidade e têm como alvo principal as sequências do gene ompA, que codifica a proteína principal de membrana externa (MOMP)'

A pesquisa da infecção endocervical por C. trachomatis em estudantes universitárias se faz necessária, pois, apesar de se tratar de uma população de mulheres conhecedoras das medidas de prevenção das IST desde a educação básica, apresenta maior exposição aos fatores de risco comportamentais ${ }^{20,21,22,23}$. Os objetivos deste estudo foram demonstrar a prevalência da infecção endocervical por C. trachomatis em estudantes de uma universidade da capital e de três de seus campi do interior do estado do Pará, Amazônia, Brasil, e investigar a sua associação com características sociodemográficas,comportamentais e de queixa ginecológica dessa população.

\section{MATERIAIS E MÉTODOS}

Foi realizado um estudo transversal de base populacional/comunitária em demanda espontânea de estudantes de quatro campi de uma universidade pública no estado do Pará, no período de setembro de 2010 a outubro de 2014: campus de Belém (Capital), Bragança (Interior 1), Castanhal (Interior 2) e Altamira (Interior 3). estudo investigou estudantes universitárias dos quatro campi que já tinham vida sexual, que possuíam idade igual ou superior a 18 anos e desejavam realizar o exame preventivo do câncer do colo do útero (PCCU). Não foram investigadas as estudantes grávidas, menstruadas ou que haviam realizado o exame de PCCU há menos de um ano.

As estudantes incluídas no estudo concordaram em participar da pesquisa mediante a assinatura do Termo de Consentimento Livre e Esclarecido (TCLE), e, após essa assinatura, as universitárias preencheram - protocolo de pesquisa que abordou as variáveis investigadas, tais como: idade, estado civil, tabagismo, idade do início da vida sexual, uso de preservativo masculino, média de parceiros na vida sexual e presença de alguma queixa ginecológica - corrimento vaginal, odor, prurido, dismenorreia, colporragia e disúria.

Este estudo é parte de um projeto de extensão universitária denominado "Ações de prevenção de doenças infecciosas integradas à saúde estudantil" e teve aprovação dos Comitês de Ética em Pesquisa em Seres Humanos do Instituto de Ciências da Saúde e do Núcleo de Medicina Tropical (NMT), ambos da Universidade Federal do Pará (UFPA), por meio dos projetos de pesquisa "Avaliação da citologia na prevenção e detecção precoce do câncer" e "Detecção e genotipagem de Chlamydia trachomatis em estudantes universitárias atendidas no Laboratório de Citopatologia da UFPA: análise citológica e molecular", sob os pareceres $n^{\circ} 173 / 08$, de 4 de novembro de 2008, e $n^{\circ} 103.571 / 2012$, de 21 de setembro de 2012, respectivamente.

As amostras de secreção endocervical foram obtidas com o auxílio de escova endocervical, durante o exame de PCCU, pela equipe de profissionais do Laboratório de Citopatologia do Instituto de Ciências Biológicas da UFPA. Após a confecção do esfregaço do PCCU, a escova endocervical foi lavada em $600 \mu \mathrm{L}$ de solução fisiológica 0,9\% em microtubo de $1,5 \mathrm{~mL}$.

As técnicas moleculares foram realizadas no Laboratório de Biologia Molecular e Celular (LBMC) do NMT/UFPA. A extração de DNA foi realizada utilizando-se $O$ protocolo modificado de Isola et al. ${ }^{24}$. O DNA genômico foi extraído pelo método do fenol/clorofórmio-álcool isoamílico, utilizando-se $300 \mu \mathrm{L}$ da amostra.

A amplificação do fragmento de $270 \mathrm{pb}$ do gene da $\beta$-globina humana foi utilizada para o controle de qualidade da extração do DNA, pela reação em cadeia mediada pela polimerase (PCR). Foram utilizados 3,5 $\mu \mathrm{L}$ de GoTaq $^{\circledR}$ Green Master Mix (Promega, Madison, Wisconsin, EUA), 2,0 $\mu \mathrm{L}$ de água, 0,5 $\mu \mathrm{L}$ do DNA, $0,5 \mu \mathrm{L}$ (pmol) de cada oligonucleotídeo G73 (5'-GAAGAGCCAAGGACAGGTAC-3') e G74 (5'-CAACTTCATCCACGTTCACC-3') ${ }^{25}$, com volume final de $7 \mu \mathrm{L}$. 
Uma Seminested PCR foi utilizada para a amplificação parcial (224 pb) do gene ompA [(AF304857 / National Center for Biotechnological Information (www.ncbi.nlm.nih.gov)] de C. trachomatis, empregando-se a metodologia modificada de Jalal et al. ${ }^{26}$. Na primeira PCR, foram utilizados 6,0 $\mu \mathrm{L}$ de GoTaq $^{\circledR}$ Green Master Mix (Promega, Madison, Wisconsin, EUA), 3,0 $\mu \mathrm{L}$ de água estéril, $1,0 \mu \mathrm{L} \quad(10 \mathrm{pmol})$ de cada oligonucleotídeo P3 (5'-AAACWGATGTGAATAAAGARTT-3') e P4 (5'-TCCCASARAGCTGCDCGAGC-3') e 1,0 $\mu \mathrm{L}$ de DNA genômico. Na segunda etapa, foram utilizados 6,0 $\mu \mathrm{L}$ de GoTaq $^{\circledR}$ Green Master Mix (Promega, Madison, Wisconsin, EUA), 3,5 $\mu \mathrm{L}$ de água estéril, 1,0 $\mu \mathrm{L}(10 \mathrm{pmol})$ de cada oligonucleotídeo CT P6 (5'-TGGGATCGYTTTGATGTATTYTGT-3') e P4 e 0,5 $\mu \mathrm{L}$ do produto da primeira amplificação. As duas reações tiveram um volume final de 12,0 $\mu \mathrm{L}$. As PCRs foram realizadas no termociclador Biocycler MJ96G (Applied
Biosystems, Foster City, Califórnia, EUA), seguindo 35 ciclos, nos quais a temperatura inicial foi de $94{ }^{\circ} \mathrm{C}$ por 4 min, seguida da desnaturação a $94{ }^{\circ} \mathrm{C}$ por $40 \mathrm{~s}$, da hibridização a $54{ }^{\circ} \mathrm{C}$ durante $30 \mathrm{~s}$, temperatura de ativação da Taq DNA polimerase e extensão a $72{ }^{\circ} \mathrm{C}$ por 1 min, seguida de temperatura de extensão final de $72{ }^{\circ} \mathrm{C}$ por $10 \mathrm{~min}$ e, por fim, resfriamento a $10{ }^{\circ} \mathrm{C}$ por $3 \mathrm{~min}$.

Os produtos das amplificações parciais do gene da $\beta$-globina humana e do gene ompA foram submetidos à eletroforese $(50 \mathrm{~V}, 100 \mathrm{~A}, 60 \mathrm{~min})$ em gel de agarose a $2 \%$, corado com brometo de etídio $(0,5 \mathrm{mg} / \mathrm{mL})$ e submerso em TAE $1 X$ (Tris- $\mathrm{HCl} 10 \mathrm{mM}, \mathrm{pH}=8$; EDTA $1 \mathrm{mM}$; acetato). Após a eletroforese, os produtos de amplificação foram visualizados sobre luz ultravioleta em transiluminador (Vilber Lourmat, Alemanha) e comparados ao marcador de peso molecular de 100 pb PlusDNA Ladder (Invitrogen, Carlsbad, Califórnia, EUA) (Figuras 1 e 2).

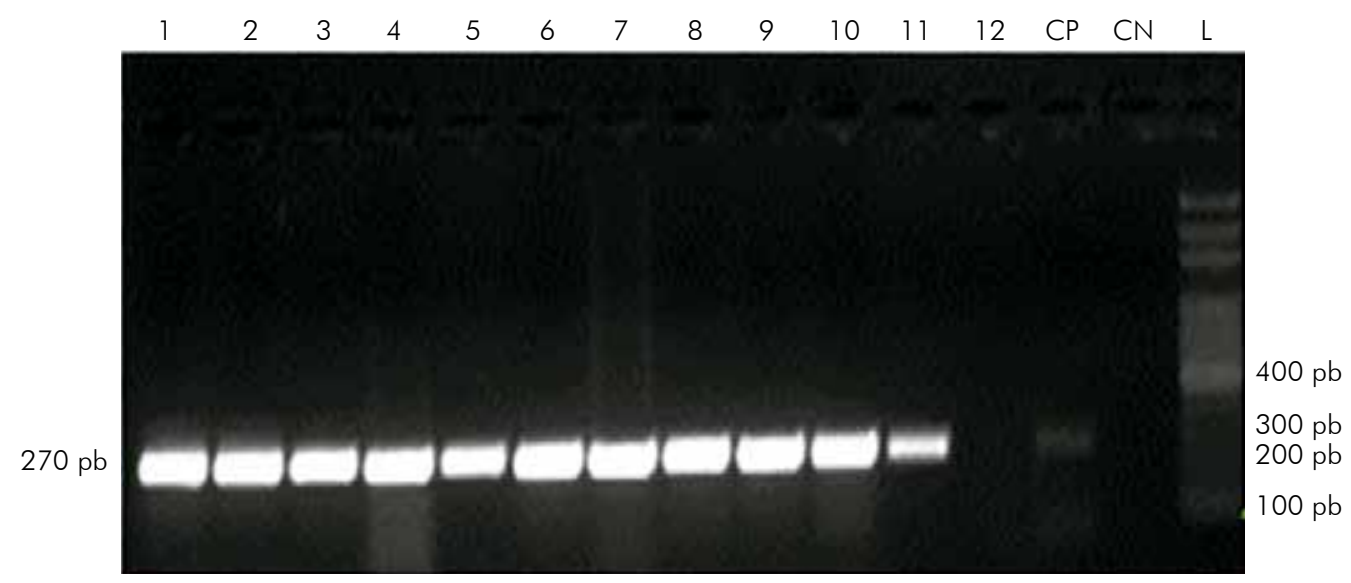

Fonte: LBMC/NMT/UFPA.

Colunas 1-11: Amostras positivas; Coluna 12: Amostra negativa; CP: Controle positivo; CN: Controle negativo; L: Marcador de peso molecular de 100 pb Plus DNA Ladder (Invitrogen, Carlsbad, Califórnia, EUA) obtido em transiluminador (Vilber Lourmat, Alemanha).

Figura 1 - Foto documentação da amplificação do fragmento de 270 pb do gene $\beta$-globina humana em gel de agarose a $2 \%$

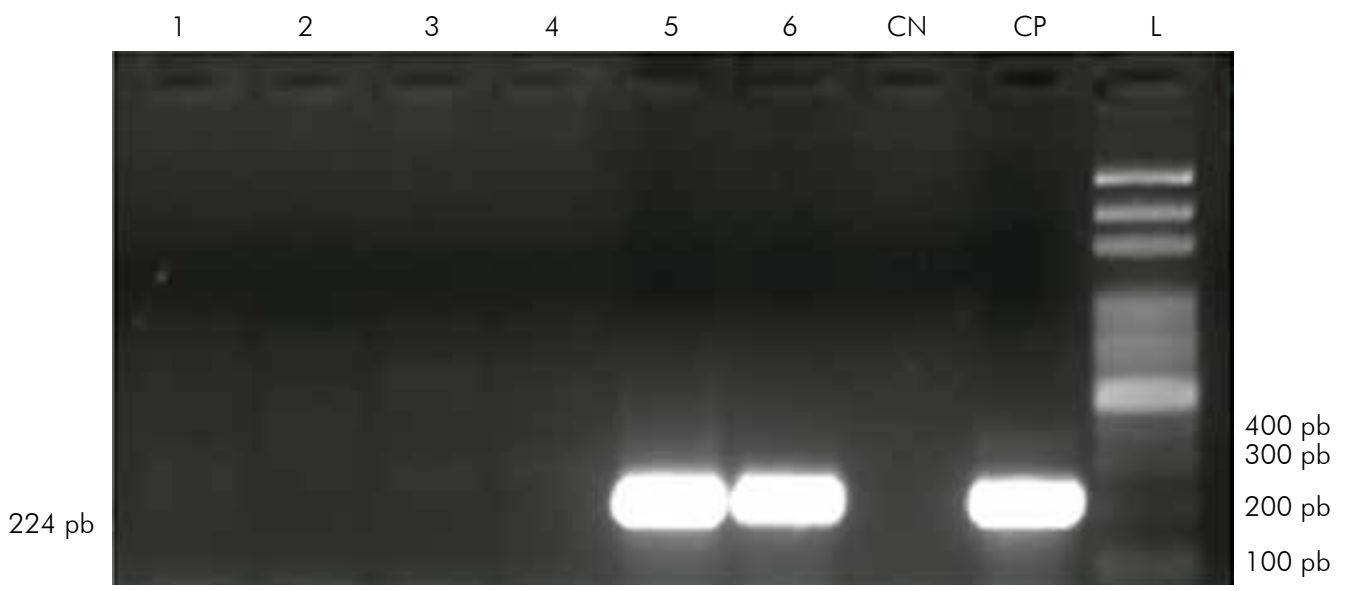

Fonte: LBMC/NMT/UFPA.

Colunas 1-4: Amostras negativas; Colunas 5-6: Amostras positivas; CN: Controle negativo; CP: Controle positivo; L: Marcador de peso molecular de 100 pb Plus DNA Ladder (Invitrogen, Carlsbad, Califórnia, EUA) obtido em transiluminador (Vilber Lourmat, Alemanha).

Figura 2 - Foto documentação da amplificação do fragmento de 224 pb do gene ompA de C. trachomatis em gel de agarose a $2 \%$ 
Os dados coletados foram armazenados em planilha do programa Microsoft Excel 2007. O programa BioEstat v5.0 foi utilizado para análise e testes estatísticos. Foi utilizado o teste de Lillefors, para verificar o padrão de normalidade, e o teste de Mann-Whitney, para comparar as medianas das idades das estudantes. Foi utilizada a estimação de parâmetros, para analisar as prevalências, e o teste de odds ratio (OR) foi utilizado para verificar a associação de variáveis sociodemográficas, comportamentais e de queixa ginecológica com a positividade para $\mathrm{C}$. trachomatis. $\mathrm{O}$ $p \leq 0,05$ foi considerado estatisticamente significativo para um intervalo de confiança (IC) de 95\%.

\section{RESULTADOS}

Entre as 454 universitárias investigadas, 11,9\% [54/454 (IC 95\% 8,9-14,9)] foram identificadas com a infecção endocervical por $C$. trachomatis. A infecção se mostrou em 10,4\% [36/345 (IC 95\% 7,2-13,7)] das estudantes do campus Capital e em 16,5\% [18/109 (IC 95\% 10,3-24,6)] das universitárias dos campi do interior. Não houve diferenças significativas entre as prevalências da capital e do interior [ $p=0,12$ (IC 95\% $0,32-1,13)$ ] (Tabela 1). Nos campi do interior, foram observadas as frequências de $7,1 \%(2 / 28)$ para 0 campus Interior 1, 22,2\% (6/27) para o campus Interior 2 e 18,5\% (10/54) para o campus Interior 3 .

Tabela 1 - Prevalências da infecção endocervical por C. trachomatis em estudantes universitárias da capital e do interior do estado do Pará, Brasil, setembro de 2010 a outubro de 2014

\begin{tabular}{|c|c|c|c|c|c|c|c|c|}
\hline & \multicolumn{2}{|c|}{ CT (-) } & \multicolumn{3}{|c|}{$\mathrm{CT}(+)$} & \multirow{2}{*}{ OR } & \multirow{2}{*}{ IC 95\% } & \multirow{2}{*}{$p$} \\
\hline & $N$ & $\%$ & $N$ & $\%$ & IC 95\% & & & \\
\hline Geral $(N=454)$ & 400 & 88,1 & 54 & 11,9 & $8,9-14,9$ & & & \\
\hline Capital $(\mathrm{N}=345)$ & 309 & 89,6 & 36 & 10,4 & $7,2-13,7$ & & & \\
\hline Interior $(N=109)$ & 91 & 83,5 & 18 & 16,5 & $10,3-24,6$ & 1,07 & $7, \angle 0-0,10$ & 0,12 \\
\hline
\end{tabular}

OR: Teste de odds ratio; IC 95\%: Intervalo de confiança; CT (-): Negativo para a infecção por C. trachomatis; CT (+): Positivo para a infecção por C. trachomatis.

Tabela 2 - Características sociodemográficas, comportamentais e queixas ginecológicas das estudantes universitárias investigadas e com infecção por C. trachomatis no estado do Pará, Brasil, setembro de 2010 a outubro de 2014

\begin{tabular}{|c|c|c|c|c|c|c|}
\hline \multirow{2}{*}{ Características } & \multicolumn{2}{|c|}{ Total } & \multicolumn{2}{|c|}{ Positivo } & \multirow{2}{*}{$\mathrm{p}$} & \multirow{2}{*}{ IC 95\% } \\
\hline & N & $\%$ & $\mathrm{~N}$ & $\%$ & & \\
\hline \multicolumn{7}{|l|}{ Idade } \\
\hline$<25$ anos & 162 & 35,7 & 18 & 11,1 & \multirow{2}{*}{0,81} & \multirow{2}{*}{$0,49-1,62$} \\
\hline$\geq 25$ anos & 292 & 64,3 & 36 & 12,3 & & \\
\hline \multicolumn{7}{|l|}{ Campus } \\
\hline Capital & 345 & 76,0 & 36 & 10,4 & \multirow{2}{*}{0,12} & \multirow{2}{*}{$0,32-1,09$} \\
\hline Interior & 109 & 24,0 & 18 & 16,5 & & \\
\hline \multicolumn{7}{|l|}{ Estado civil } \\
\hline Solteira & 391 & 86,1 & 47 & 12,0 & \multirow{2}{*}{0,99} & \multirow{2}{*}{$0,47-2,54$} \\
\hline Casada & 63 & 13,9 & 7 & 11,1 & & \\
\hline \multicolumn{7}{|l|}{ Início da vida sexual } \\
\hline$<15$ anos & 29 & 6,4 & 4 & 13,8 & \multirow{2}{*}{0,90} & \multirow{2}{*}{$0,37-3,28$} \\
\hline$\geq 15$ anos & 425 & 93,6 & 50 & 11,8 & & \\
\hline \multicolumn{7}{|l|}{ Uso de preservativo } \\
\hline Sim & 296 & 65,2 & 32 & 10,8 & \multirow{2}{*}{0,41} & \multirow{2}{*}{$0,42-1,34$} \\
\hline Não & 158 & 34,8 & 22 & 13,9 & & \\
\hline \multicolumn{7}{|c|}{ Parceiros sexuais na vida } \\
\hline 1 & 113 & 24,9 & 15 & 13,3 & \multirow{2}{*}{0,72} & \multirow{2}{*}{$0,63-2,24$} \\
\hline$>1$ & 341 & 75,1 & 39 & 11,4 & & \\
\hline \multicolumn{7}{|c|}{ Queixas ginecológicas } \\
\hline $\operatorname{Sim}$ & 349 & 76,9 & 36 & 10,3 & \multirow{2}{*}{0,73} & \multirow{2}{*}{$0,44-1,62$} \\
\hline Não & 105 & 23,1 & 18 & 17,1 & & \\
\hline
\end{tabular}

Na variável idade, os dados foram apresentados como média \pm DP (desvio padrão). Os dados foram apresentados como $\mathrm{N}$ e \% utilizando-se o teste odds ratio. IC 95\%: Intervalo de confiança. 
A idade das universitárias variou de 18 a 67 anos, com média de 25,19 anos (IC 95\%, DP $\pm 6,05$ ), predominantemente do campus Capital (76,0\%), solteiras $(86,1 \%)$, com início da vida sexual aos 15 anos de idade ou mais $(93,6 \%)$, que usavam preservativo masculino nas relações sexuais $(65,2 \%)$, que tiveram mais de um parceiro sexual $(75,1 \%)$ e que apresentavam alguma queixa ginecológica $(76,9 \%)$ (Tabela 2).

A idade média das universitárias que apresentavam a infecção foi de 24,87 anos (IC 95\%, DP \pm 6,13) e essa infecção foi observada em 12,0\% das solteiras, em 13,8\% daquelas que iniciaram a vida sexual com menos de 15 anos de idade, em 13,9\% das que não usavam preservativo masculino nas relações sexuais, em $13,3 \%$ das que tiveram somente um parceiro sexual e em $17,1 \%$ das que não apresentavam queixas ginecológicas (Tabela 2).

\section{DISCUSSÃO}

A epidemiologia da infecção endocervical por C. trachomatis ainda é pouco esclarecida, principalmente na Região Norte do Brasil, devido a ainda não ser de notificação compulsória e pela ausência de exames sensíveis e de baixo custo na rede pública. $\bigcirc$ que se sabe sobre essa prevalência está baseado em estudos de populações específicas, como este realizado em uma população de estudantes universitárias. A falta desses dados inviabiliza a formulação de esquemas de controle e prevenção da infecção por parte do sistema público de saúde do país. Não há registros de investigação da infecção endocervical por C. trachomatis exclusivamente com estudantes universitários brasileiros.

Estudos envolvendo universitários de outros países, como Coreia do Sul $(3,1 \%)^{27}$, Argentina $(5,9 \%)^{28}$ e Inglaterra $(3,4 \%)^{29}$, demonstraram prevalências menores que a do presente estudo $(11,9 \%)$. No entanto, prevalência semelhante $(9,7 \%)$ da infecção foi encontrada em universitários do Alabama, Mississipi e Geórgia, nos EUA, tendo sido associada a estudantes mais jovens ${ }^{21}$.

$\bigcirc$ presente estudo se preocupou em investigar a infecção endocervical por $C$. trachomatis não somente em estudantes universitárias da capital do estado do Pará, mas também naquelas dos campi do interior, esperando encontrar uma proporção menor no interior. No entanto, as prevalências da capital e do interior não demonstraram diferença significativa, mas se faz necessário aumentar o tamanho amostral para confirmação da aparente maior proporção dessa infecção no interior.

A prevalência da infecção não difere significativamente das encontradas em outros estudos do Brasil, os quais foram realizados em populações femininas urbanas, com variados graus de instrução, como nos estados do Rio Grande do Norte $(10,9 \%)^{13}$, Goiás $(9,6 \%)^{14}$, Paraná $(12,7 \%)^{17}$ e Rio Grande do Sul $(11,0 \%)^{15}$. Apenas nos estados da Bahia $(31,0 \%)^{18}$ e de
Pernambuco $(23,8 \%)^{16}$ foram registradas prevalências maiores, porém com tamanho amostral inferior ao utilizado neste estudo.

presente estudo utilizou a metodologia baseada na amplificação de ácidos nucleicos, que é recomendada para a triagem dessa infecção'; porém estudos anteriores, baseados em técnicas sorológicas de C. trachomatis, mostraram altas frequências algumas comunidades da Amazônia ${ }^{30,31}$. As prevalências encontradas na capital Manaus $(4,3 \%)^{11} \mathrm{e}$ na zona rural $(6,4 \%)^{12}$ do estado do Amazonas foram inferiores às das estudantes universitárias do presente estudo. Por outro lado, um estudo de base clínica que recrutou mulheres atendidas em uma maternidade de referência, em Belém, registrou prevalência semelhante $(11,0 \%)^{19}$.

$\mathrm{Na}$ Nigéria, C. trachomatis atingiu uma alta prevalência $(30,2 \%)$ em infecções sexuais nos universitários e, embora tenha sido utilizada a técnica de detecção sorológica, foi a única prevalência que se mostrou superior a deste estudo1,32. $O$ pequeno tamanho amostral de alguns campi do interior do estado do Pará, juntamente com o possível viés de resposta de preenchimento do questionário, pode ter influenciado a falta de associação das variáveis analisadas com a infecção. As universitárias podem ter respondido ao questionário de acordo com medidas socialmente aceitáveis, com chances de mascarar informações quanto ao respectivo comportamento sexual.

A presença de algum tipo de queixa ginecológica foi uma característica amplamente relatada pelas universitárias de todos os campi estudados; porém, os sintomas da infecção por C. trachomatis são inespecíficos, e outras etiologias podem ser causadoras dos sinais e sintomas ginecológicos relatados ${ }^{33}$.

Esperava-se encontrar baixas frequências dessa infecção entre universitárias, uma vez que elas apresentam um maior grau de instrução e vivenciam as medidas profiláticas desde o ensino médio, em que são trabalhados temas extracurriculares, como a prevenção das $\mathrm{IST}^{34}$. Porém, a prevalência da infecção encontrada no presente estudo pode ser consequência da falta das medidas preventivas rotineiras dessas infecções ${ }^{35}$.

\section{CONCLUSÃO}

A prevalência da infecção endocervical por C. trachomatis em universitárias do estado do Pará se assemelhou à média encontrada na população brasileira. Não foi encontrada diferença significativa na prevalência da infecção entre estudantes da capital e do interior do Estado. A infecção não se mostrou associada às condições sociodemográficas e comportamentais das universitárias investigadas. Torna-se necessário ampliar - estudo para confirmar a prevalência da infecção nos campi do interior do Estado e sua ausência de correlação com os fatores investigados. 


\section{AGRADECIMENTOS}

Laboratório de Citopatologia, Instituto de Ciências Biológicas, UFPA.

\section{APOIO FINANCEIRO}

Superintendência de Assistência Estudantil e Pró-Reitoria de Extensão da UFPA.

\section{REFERÊNCIAS}

1 Papp JR, Schachter J, Gaydos CA, Van Der Pol B. Recommendations for thelaboratory-based detection of Chlamydia trachomatis and Neisseria gonorrhoeae - 2014. MMWR Recomm Rep. 2014 Mar;63(RR-02): 1 - 19.

2 European Centers for Disease Prevention and Control. Sexually transmitted infections in Europe 2011. Stockholm: ECDC;2013. (Surveillance report).

3 Lewis D, Newton DC, Guy RJ, Ali H, Chen MY, Fairley CK, et al. The prevalence of Chlamydia trachomatis infection in Australia: a systematic review and meta-analysis. BMC Infect Dis. 2012 May; 12:113.

4 Johnson LF, Coetzee DJ, Dorrington RE. Sentinel surveillance of sexually transmitted infections in South Africa: a review. Sex Transm Infect. 2005 Aug;81 (4):287-93.

5 Ramadhani AM, Derrick T, Holland MJ, Burton MJ. Blinding trachoma: systematic review of rates and risk factors for progressive disease. PLoS Negl Trop Dis. 2016 Aug;10(8):e0004859.

6 Ceovic R, Gulin SJ. Lymphogranuloma venereum: diagnostic and treatment challenges. Infect Drug Resist. 2015 Mar;8:39-47.

7 Manavi K. A review on infection with Chlamydia trachomatis. Best Pract Res Clin Obstet Gynaecol. 2006 Dec;20(6):941-51.

8 Mania-Pramanik J, Kerkar S, Sonawane S, Mehta P, Salvi V. Current Chlamydia trachomatis infection, a major cause of infertility. J Reprod Infertil. 2012 Oct-Dec;13(4):204-10.

9 Ahmadi A, Khodabandehloo M, Ramazanzadeh R, Farhadifar F, Roshani D, Ghaderi E, et al. The relationship between Chlamydia trachomatis genital infection and spontaneous abortion. J Reprod Infertil. 2016 Apr-Jun; 17(2): 110-6.

10 Oliveira FA, Pfleger V, Lang K, Heukelbach J, Miralles I, Fraga F, et al. Sexually transmitted infections, bacterial vaginosis, and candidiasis in women of reproductive age in rural Northeast Brazil: a population-based study. Mem Inst Oswaldo Cruz. 2007 Sep; 102(6):751-6.

11 Silva LCF, Miranda AE, Batalha RS, Sabino C, Dib ECD, Costa CM, et al. Chlamydia trachomatis infection among HIV-infected women attending in AIDS clinic in the city of Manaus, Brazil. Braz J Infect Dis. 2012 Jul-Aug; 16(4):335-8.
12 Rocha DAP, Barbosa Filho RAA, Mariño JM, Santos CMB. "Hidden" sexually transmitted infections among women in primary care health services, Amazonas, Brazil. Int J STD AIDS. 2014 Oct;25(12):878-86.

13 Magalhães PAF, Miranda CAN, Lima ÉG, Moizéis RNC, Lima DBS, Cobucci RNO, et al. Genital tract infection with Chlamydia trachomatis in women attended at a cervical cancer screening program in Northeastern from Brazil. Arch Gynecol Obstet. 2015 May;291(5):1095102.

14 Lima YAR, Turchi MD, Fonseca ZC, Garcia FLB, Cardoso FAB, Reis MNG, et al. Sexually transmitted bacterial infections among young women in Central Western Brazil. Int J Infect Dis. 2014 Aug;25: 16-21.

15 Garcês AX, Martinez AMB, Gonçalves CV, Germano FN, Barral MFM, Vieira VC. Prevalência de Chlamydia trachomatis e fatores de risco associados à infecção detectada em amostra endocervical. Rev Bras Ginecol Obstet. 2013 ago;35(8):379-83

16 Tavares MCM, Macêdo JL, Lima Júnior SF, Heráclio SA, Amorim MMR, Maia MMD, et al. Chlamydia trachomatis infection and human papillomavirus in women with cervical neoplasia in PernambucoBrazil. Mol Biol Rep. 2014 Feb;41(2):865-74.

17 Abreu ALP, Nogara PRB, Souza RP, Silva MC, Uchimura NS, Zanko RL, et al. Molecular detection of HPV and Chlamydia trachomatis infections in Brazilian women with abnormal cervical cytology. Am J Trop Med Hyg. 2012 Dec;87(6):1 149-51.

18 Machado MSC, Costa e Silva BFB, Gomes ILC, Santana IU, Grassi MFR. Prevalence of cervical Chlamydia trachomatis infection in sexually active adolescents from Salvador, Brazil. Braz J Infect Dis. 2012 May-Apr;16(2):188-91.

19 Brasiliense DM, Borges BN, Ferreira WAS. Genotyping and prevalence of Chlamydia trachomatis infection among women in Belém, Pará, northern Brazil. J Infect Dev Ctries. 2016 Feb; 10(2): 134-7.

20 Bearinger LH, Sieving RE, Ferguson J, Sharma V. Global perspectives on the sexual and reproductive health of adolescents: patterns, prevention, and potential. Lancet. 2007 Apr;369(9568):1220-31.

21 James $A B$, Simpson TY, Chamberlain WA. Chlamydia prevalence among college students: reproductive and public health implications. Sex Transm Dis. 2008 Jun;35(6):529-32. 
22 Pinto VM, Szwarcwald CL, Baroni C, Stringari LL, Inocêncio LA, Miranda AE. Chlamydia trachomatis prevalence and risk behaviors in parturient women aged 15 to 24 in Brazil. Sex Transm Dis. 2011 Oct;38(10):957-61.

23 Bender N, Herrmann B, Andersen B, Hocking JS, van Bergen J, Morgan J, et al. Chlamydia infection, pelvic inflammatory disease, ectopic pregnancy and infertility: cross-national study. Sex Transm Infect. 2011 Dec;87(7):601-8.

24 Isola J, DeVries S, Chu L, Ghazvini S, Waldman F. Analysis of changes in DNA sequence copy number by comparative genomic hybridization in archival paraffin-embedded tumor samples. Am J Pathol. 1994 Dec;145(6):1301-8.

25 Greer CE, Lund JK, Manos MM. PCR amplification from paraffin-embedded tissues: recommendations on fixatives for long-term storage and prospective studies. PCR Methods Appl. 1991 Aug;1 (1):46-50.

26 Jalal H, Stephen $H$, Alexander S, Carne C, Sonnex C. Development of real-time PCR assays for genotyping of Chlamydia trachomatis. J Clin Microbiol. 2007 Aug;45(8):2649-53.

27 Lee SJ, Cho YH, Ha US, Kim SW, Yoon MS, Bae K. Sexual behavior survey and screening for chlamydia and gonorrhea in university students in South Korea. Int J Urol. 2005 Feb; 12(2): 187-93.

28 Occhionero M, Paniccia L, Pedersen D, Rossi $G$, Mazzucchini $H$, Entrocassi A, et al. Prevalencia de la infección por Chlamydia trachomatis y factores de riesgo de infecciones transmisibles sexualmente en estudiantes universitarios. Rev Argent Microbiol. 2015 ene-mar;47(1):9-16.
29 Aldeen T, Jacobs J, Powell R. Screening university students for genital chlamydial infection: another lesson to learn. Sex Health. 2010;7(4):491-4.

30 Ishak MOG, Ishak R, Cruz ACR, Santos DEM, Salgado U. Chlamydial infection in the Amazon region of Brazil. Trans R Soc Trop Med Hyg. 1993 Jan-Feb;87(1):60-2.

31 Ishak MOG, Ishak R. O impacto da infecção por Chlamydia em populações indígenas da Amazônia brasileira. Cad Saude Publica. 2001 mar-abr; 17(2):385-96.

32 Arinze AUH, Onyebuchi NV, Isreal J. Genital Chlamydia trachomatis infection among female undergraduate students of University of Port Harcourt, Nigeria. Niger Med J. 2014 JanFeb;55(1):9-13.

33 Afrakhteh M, Mahdavi A, Beyhaghi $H$, Moradi A, Gity S, Zafargandi S, et al. The prevalence of Chlamydia trachomatis in patients who remained symptomatic after completion of sexually transmitted infection treatment. Iran J Reprod Med. 2013 Apr; 11 (4):285-92.

34 Ministério da Saúde (BR). Secretaria de Vigilância em Saúde. Saúde e prevenção nas escolas: guia para a formação de profissionais de saúde e de educação. Brasília: Ministério da Saúde; 2006. (Série A. Normas e manuais técnicos).

35 Silva ASN, Silva BLCN, Silva Júnior AF, Silva MCF, Guerreiro JF, Sousa ASCA. Início da vida sexual em adolescentes escolares: um estudo transversal sobre comportamento sexual de risco em Abaetetuba, Estado do Pará, Brasil. Rev Pan-Amaz Saude. 2015 set;6(3):27-34. 